\title{
Causes of Removal of metallic hardware employed in oral and maxillofacial surgery - A cross sectional survey.
}

\footnotetext{
1. BDS, M.Phil (Oral Pathology) Assistant Professor Oral Pathology Watim Dental College Rawalpindi.

2. BDS, FCPS

Assistant Professor Oral \&

Maxillofacial

Watim Dental College Rawalpindi.

3. BDS, MCPS (Oral and Maxillofacial Surgery)

Dentist

Hamza Camp, Rawalpindi.

4. BDS, FCPS

Assistant Professor Prosthodontics Watim Dental College Rawalpindi.

5. BDS, FCPS

Assistant Professor Operative Dentistry

Watim Dental College Rawalpindi.

6. BDS

Demonstrator Orthodontics NUMS.
}

Correspondence Address:

Dr. Gulmina Saeed Orakzai

Department of Oral Pathology

Watim Dental College Rawalpindi.

gulmina_saeed@yahoo.com

Article received on:

01/02/2021

Accepted for publication:

$10 / 04 / 2021$

\section{INTRODUCTION}

Treating craniomaxillofacial trauma involves restoring both function and form of facial bony skeleton and the surrounding soft tissue envelope. However, this was not possible until the introduction of open reduction and rigid internal fixation procedures that oral surgeons were able to restore the facial skeleton. ${ }^{1}$ Removing metal plates after oral and maxillofacial surgery not an uncommon procedure. ${ }^{2}$ Since its usage it has been considered as a source of morbidity. However, many surgeons advocate removal of plates based on their experiences, practices and observations, others suggest leaving plates in situ because of cost effectiveness. A wide variety of diseases in oral and maxillofacial region require fixation such as fractures, pathology, tumors, congenital and developmental anomalies. After surgical management the bony skeleton is either fixed or reinforced with the hardware which might be in the forms of manipulate, micro plate, reconstruction plate or distractor. Metallic hardware use in form of titanium has long been used in maxillofacial surgery. Titanium is considered a trustworthy metal for its unique ability to bind with the bone, a characteristic known as Osseo integration. Therefore, plates made of Titanium are widely used. ${ }^{3,4}$ Titanium is considered biocompatible and biologically inert but its prolonged presence can cause complications leading to second surgical intervention which are performed either under local or general anesthesia to remove titanium hardware. There is a dearth of clinical guidelines for safe practices to remove tru-dynamic plating system after oral and maxillofacial surgical fixation. ${ }^{5}$ A clinical study reported the rated the rate for metallic plate removal ranged 2.3-28.1\% among patient who suffered trauma. ${ }^{6}$ This fact is further supported by Hernandez et al. ${ }^{7}$ They observed that the plates were a source of infection 
among almost half of the patient and removal of entire metal hardware was necessary for infection management. Whereas, Raja et al. examined the orthognathic procedures and recommended the partial removal of tru-dynamic plating system after oral and maxillofacial surgical fixation ranging between $9.5 \%-27.5 \%$, although some surgical centers advocate removal of all plates. ${ }^{5}$ Furthermore, two meta-analysis highlights that removal ranged $12-22 \%$ among patients with fractured angle of mandible due to number of causes including number of plates, types of plates i.e. compression versus non-compression, type of screw i.e. mono versus bicortical contributing to the varying rate of complications. ${ }^{8,9}$

Therefore, this study was set out to investigate the causes for removal of tru-dynamic plating system among patients who underwent oral and maxillofacial surgical procedures.

\section{MATERIAL \& METHODS}

This descriptive cross-sectional study was conducted at oral and maxillofacial department of Armed Forces Institute of Dentistry. Census sampling was employed to recruit participants in the study. Participation was voluntary and anonymous. Approval from research board, permission from institutional head and informed consent was obtain from study participants. We collected the data over the period of 2.5 years from January 2016 to June 2018 all patients who reported to oral and maxillofacial surgery department of Armed Forces Institute of Dentistry and underwent removal of metallic hardware were included, however patients under 18 years of age were excluded from the study. All plates used were from Tru-Dynamic Plating System.

Questionnaire was designed to collect information pertinent to reasons for plate removal, time between implantation of plates and their removal, location of implant and demographic variables. Data was coded and entered into SPSS 23.0 version for analysis.

\section{RESULTS}

A total of 60 patients reported to AFID with complaints regarding metallic hardware (i.e. micro mini and reconstruction plates) who subsequently underwent plate removal under local or general anesthesia. Study participants were predominantly male $34(56.7 \%)$ as compared to the female patients $26(43.3 \%)$. The metal plates were removed among the patients' age ranged between 20-40 years. Duration to retain the plate's prior surgical removal ranged 3-36 months. There were 26 patients whose metal plates were removed after 6-12 months of open reduction internal fixation procedure. (Table-I).

\begin{tabular}{|l|c|}
\hline \multicolumn{1}{|c|}{ Duration } & N (\%) \\
\hline less than 6 months & $20(33.3 \%)$ \\
\hline 6 to 12 months & $26(43.3 \%)$ \\
\hline 12 to 18 months & $6(10.0 \%)$ \\
\hline 24 to 30 months & $4(6.7 \%)$ \\
\hline more than 30 months & $4(6.7 \%)$ \\
\hline Total & $60(100 \%)$ \\
\hline
\end{tabular}

Table-I. Table showing duration of plate removal.

Causes of plate removal were evaluated thoroughly and infection was found to be most common etiological factor in $18(30 \%)$ of patients followed by non-union in 8 (13.3\%) patients. Pain, palpable plates, recurrence of lesion, psychological, and prosthesis rehabilitation contributed $6.7 \%$ each towards removal of hardware. While least identified causes included intolerance, patient's request and diagnostic procedure i.e. MRI 3.3\% each. (Table-II).

\begin{tabular}{|l|c|}
\hline \multicolumn{1}{|c|}{ Causes } & N (\%) \\
\hline Infection & $18(30 \%)$ \\
\hline Non-union & $8(13.3 \%)$ \\
\hline Planned Removal & $8(13.3 \%)$ \\
\hline Pain & $4(6.7 \%)$ \\
\hline palpable plate & $4(6.7 \%)$ \\
\hline Recurrence of Lesion & $4(6.7 \%)$ \\
\hline Psychological & $4(6.7 \%)$ \\
\hline Prosthetic Rehabilitation & $4(6.7 \%)$ \\
\hline Intolerance & $2(3.3 \%)$ \\
\hline Patient's Request & $2(3.3 \%)$ \\
\hline MRI & $2(3.3 \%)$ \\
\hline Total & $60(100 \%)$ \\
\hline
\end{tabular}

Table-II. Causes of plate removal. 


\begin{tabular}{|l|c|}
\hline \multicolumn{1}{|c|}{ Site } & N (\%) \\
\hline Angle of Mandible & $14(23.3 \%)$ \\
\hline Frontozygomatic buttress & $14(23.3 \%)$ \\
\hline Symphysis & $8(13.3 \%)$ \\
\hline Body of Mandible & $8(13.3 \%)$ \\
\hline zygomaticomaxillary buttress & $8(13.3 \%)$ \\
\hline Parasymphysis & $6(10 \%)$ \\
\hline Anterior Maxilla & $2(3.3 \%)$ \\
\hline Total & $60(100 \%)$ \\
\hline \multicolumn{2}{|c|}{ Table-III. Site of plate removal. } \\
\hline
\end{tabular}

Analysis showed that most plates were removed from the angle of mandible and frontozygomatic buttress cumulatively $46.6 \%$. Symphsis, body of mandible and zygomaticomaxillary buttress $13.3 \%$ each. While parasymphsis $10 \%$ and least was the anterior maxilla 3.3\%. For fixation devices removed from mandible most common site was angle of mandible (Table-III).

\begin{tabular}{|l|c|c|c|}
\hline \multicolumn{1}{|c|}{ Association } & Chi & & P-Value \\
\hline Gender --------Cause & 25.28 & 7 & 0.001 \\
\hline Gender --------Site & 11.42 & 6 & 0.076 \\
\hline Gender --------Duration & 3.00 & 3 & 0.390 \\
\hline Age ------------Cause & 79.78 & 21 & 0.001 \\
\hline Age ------------Site & 28.94 & 18 & 0.049 \\
\hline Age ------------Duration & 18.51 & 9 & 0.030 \\
\hline
\end{tabular}

Table-IV. Association of demographic variable with cause, site and duration of hardware removal.

Gender was significantly associated with the cause of hardware removal (P-Value, <0.001). Age showed significant association with cause, site and duration of removing the metallic plates (P-Value, < 0.05).

\section{DISCUSSION}

Utilization of tru-dynamic plating system to reconstruct dentofacial deformities is seen as a standard practice around the world over the past few decades. However, it is not without complicationsi.e. infections, pain and dehiscence. As a result, routine removal of plates is a surgical debate, few supporting the removal while other assert their retention. ${ }^{10,11}$

In this study a total of 60 patients reported to AFID with complaints regarding metallic hardware (i.e. micro mini and reconstruction plates) who subsequently underwent plate removal under local or general anesthesia. This study found a comparable proportion of male $56.7 \%$ and $43.3 \%$ female patients who presented for removal of metal plates. This finding is in contrast to the other studies who did not show comparable proportion between genders. ${ }^{10}$

Current study showed higher numbers of plates were removed among the patient aged 20-40 years. This finding is consistent to a study that reported high removal of plates with patient aged around 30 years. ${ }^{20}$

There is a strong association between the location of plates and their removal. In this study, 22 patients had plates removed from mandible, 2 from maxilla and 11 from zygomatic bone. For fixation devices removed from mandible most common site was angle of mandible. This is in contrast to a similar study ${ }^{4}$, but concurs with the findings of a similar study conducted in Birmingham. ${ }^{10}$ This can be attributed to the presence of external oblique ridge where the mucoperiosteum is thin and loose favoring plate exposure and infection. ${ }^{6}$

The time between insertion and removal of hardware i.e. retention period ranged from 3 to 36 months. Out of 60 patients, 26 patients had plates removed after 6 to 12 months after plate insertion showing highest incidence of plate removal. This proportion was similar to results of Bhatt and his colleagues, who also found in their research work that no plates that had been in situ for more than 30 months needed removal. ${ }^{20}$

Causes of plate removal were evaluated thoroughly and infection was found to be most common etiological factor in $18(30 \%)$ of patients followed by non-union and planned removal in 8 (13.3\%) each and pain $4(6.7 \%)$ respectively. This was in accordance to similar studies conducted by Rana et al and Bhatt et al where infection was the main reason for plates removal. ${ }^{1,10}$

When a hardware becomes infected, it causes 
hardware exposure, fistula formation, extrusion, bony nonunion and osteomyelitis, which is managed by debridement of necrotic tissue and antibiotic administration. ${ }^{2,9}$

The argument given in favor of plate removal is once the metallic hardware has served the particular purpose, it then becomes an unwanted foreign body which a tendency to cause infection and other related problems. Therefore, removal is considered a preventive measure. ${ }^{2}$ On the other hand, oral and maxillofacial surgeons who support removal of osteosynthesis devices asserts the various scientific reasons, such as high corrosion resistance and excellent biocompatibility of titanium with bone. ${ }^{20}$

Hence retaining or removing the miniplates remains a debate among medical and surgical fraternity, which may be resolved in future with the wide use of biodegradable plate. Therefore, British association of oral and maxillofacial surgeons recommend the removal of plates among symptomatic patients based on authentic clinical findings and expert judgment. This protocol is supported by the present study.

A small sample size and limited follow up were the main limitations. A multicenter study conducted in various large maxillofacial trauma centers will help establish protocols for removal or retention of plates.

\section{CONCLUSION}

The study reveals plate-related problems mostly develop with in the first year, with infection being the primary cause of plate removal. Therefore, informed consent must comprise the removal of plates if need arise. Further research in this area, will help establish protocols for retention or removal of metallic hardware in such patients.

\section{Copyright@ 10 Apr, 2021.}

\section{REFERENCES}

1. Rana Z, Khoso N, Siddiqi K. The incidence and indications for removal of osteosynthesis devices in adult trauma patients: A retrospective study. Ann Pak Inst Med Sci. 2012; 8(3):184-187.
2. Little $M$, Langford $R$, Bhanji A, Farr D. Plate removal following orthognathic surgery. Journal of CranioMaxillofacial Surgery. 2015; 43(9):1705-1709.

3. Llandro $\mathrm{H}$, Langford $\mathrm{R}$. Reasons for plate removal after treatment of orbitozygomatic complex fractures. Journal of Cranio-Maxillofacial Surgery. 2015; 43(1):1720.

4. Cahill T, Gandhi R, Allori A, Marcus J, Powers D, Erdmann $D$ et al. Hardware removal in craniomaxillofacial trauma. Annals of Plastic Surgery. 2015; 75(5):572-578.

5. Ahmed W, Bukhari S, Janjua O, Luqman U, Shah I. Bioresorbable verses titanium plates for mandibular fractures. Journal of the College of Physicians and Surgeons Pakistan. 2013; 23(7):480-483.

6. Yamamoto K, Matsusue Y, Horita S, Murakami K, Sugiura T, Kirita T. Routine removal of the plate after surgical treatment for mandibular angle fracture with a third molar in relation to the fracture line. Annals of Maxillofacial Surgery. 2015; 5(1):77.

7. Day K, Desmond R, Magnuson J, Carroll W, Rosenthal E. Hardware removal after osseous free flap reconstruction. Otolaryngology -- Head and Neck Surgery. 2013; 150(1):40-46.

8. Thorén H, Snäll J, Kormi E, Lindqvist C, SuominenTaipale L, Törnwall J. Symptomatic plate removal after treatment of facial fractures. Journal of CranioMaxillofacial Surgery. 2010; 38(7):505-510.

9. O'Connell J, Murphy C, Ikeagwuani O, Adley C, Kearns $\mathrm{G}$. The fate of titanium miniplates and screws used in maxillofacial surgery: A 10 year retrospective study. International Journal of Oral and Maxillofacial Surgery. 2009; 38(7):731-735.

10. Bhatt V, Chhabra P, Dover M. Removal of miniplates in maxillofacial surgery: A follow-up study. Journal of Oral and Maxillofacial Surgery. 2005; 63(6):756-760.

11. Theodossy T, Jackson O, Petrie A, Lloyd T. Risk factors contributing to symptomatic plate removal following sagittal split osteotomy. International Journal of Oral and Maxillofacial Surgery. 2006; 35(7):598-601.

12. Falter B, Schepers S, Vrielinck L, Lambrichts I, Politis C. Plate removal following orthognathic surgery. Oral Surgery, Oral Medicine, Oral Pathology, Oral Radiology, and Endodontology. 2011; 112(6):737-743.

13. Meningaud J, Poupon J, Bertrand J, Chenevier C, GalliotGuilley M, Guilbert F. Dynamic study about metal release from titanium miniplates in maxillofacial surgery. International Journal of Oral and Maxillofacial Surgery. 2001; 30(3):185-188. 
14. Thorén H, Snäll J, Hallermann W, Kormi E, Törnwall J. Policy of routine titanium miniplate removal after maxillofacial trauma. Journal of Oral and Maxillofacial Surgery. 2008; 66(9):1901-1904.

15. Cordewener F W, Schmitz J P. The future of biodegradable osteosyntheses. Tissue Eng. 2000; 6:413-424

16. Bhatt W, Langford RJJ. Oral and maxillofacial surgery: Removal of miniplates in maxillofacial surgery: university hospital birmingham experience. Oral Maxillofac Surg. 2003; 61:553-556.

17. Steinemann S. Metal for craniomaxillofacial internal fixation implants and its physiologic implications. In: Greenberg A, Prein J, editor. Craniomaxillofacial Reconstructive and Corrective Bone Surgery. New York, NY: Springer; 2006. pp. 107-112.
18. Landes $C A$, Ballon $A$, Roth $C$. Maxillary and mandibular osteosyntheses with PLGA and P(L/DL)LA implants: A 5-year inpatient biocompatibility and degradation experience. Plast Reconstr Surg. 2006; 117:2347-2360.

19. Kim $Y$ K, Kim S G. Treatment of mandible fractures using bioabsorbable plates. Plast Reconstr Surg. 2002; 110:25-31.

20. Tuovinen V, Suuronen R, Teittinen M, Nurmenniemi P. Comparison of the stability of bio absorbable and titanium osteosynthesis materials for rigid internal fixation in orthognathic surgery: A prospective randomized controlled study in 101 patients with 192 osteotomies. Int J Oral Maxillofac Surg. 2010 Nov; 39(11):1059-65.

\begin{tabular}{|c|c|c|c|}
\hline \multicolumn{4}{|c|}{ AUTHORSHIP AND CONTRIBUTION DECLARATION } \\
\hline Sr. \# & Author(s) Full Name & Contribution to the paper & Author(s) Signature \\
\hline 1 & Gulmina Saeed Orakzai & Co-Author & \\
\hline 2 & Eruj Shuja & Author / Operating OMFS & \\
\hline 3 & Kausar Niazi & Co-Author & 4 \\
\hline 4 & Zarah Afreen & Co-Author & \\
\hline 5 & Ammarah Afreen & Co-Author & \\
\hline 6 & Omer Siddiqui & $\begin{array}{l}\text { Proof/ Statistical, Reading } \\
\text { analysis. }\end{array}$ & \\
\hline
\end{tabular}

